\title{
Measurements of Particle BaCkscatter, Extinction, AND LiDAR Ratio AT 1064 NM With the Rotational Raman METhod In Polly-XT
}

\author{
Ronny Engelmann ${ }^{1 *}$, Moritz Haarig ${ }^{1}$, Holger Baars ${ }^{1}$, Albert Ansmann ${ }^{1}$, \\ Michael Kottas ${ }^{2}$, Eleni Marinou ${ }^{2}$ \\ ${ }^{1}$ Leibniz Institute of Tropospheric Research (TROPOS), Leipzig, Germany, *Email: ronny@tropos.de, \\ ${ }^{2}$ National Observatory of Athens (NOA), Greece
}

\begin{abstract}
We replaced a 1064-nm interference filter of a Polly-XT lidar system by a 1058 -nm filter to observe pure rotational Raman backscattering from atmospheric Nitrogen and Oxygen. Polly-XT is compact Raman lidar with a Nd:YAG laser (20 $\mathrm{Hz}, 200 \mathrm{~mJ}$ at $1064 \mathrm{~nm}$ ) and a 30-cm telescope mirror which applies photomultipliers in photoncounting mode.
\end{abstract}

We present the first measured signals at $1058 \mathrm{~nm}$ and the derived extinction profile from measurements aboard RV Polarstern and in Leipzig. In combination with another Polly-XT system we could also derive particle backscatter and lidar ratio profiles at $1064 \mathrm{~nm}$.

\section{INTRODUCTION}

The rotational Raman lidar (RRL) technique has been used for a long time, especially for temperature [1] and also for aerosol extinction [2] measurements in the atmosphere. Recently it was presented by Veselovskii et al. [3] that nowadays the availability of specially designed interference filters can enable multiwavelength lidars to use the RRL technique as a replacement for the more traditional vibrational Raman lidar technique at $532 \mathrm{~nm}$ wavelength [4]. This method is intriguing because on the one hand the RRL results in a factor of 20 more signal strength and on the other hand the assumption of the Angström exponent between elastic and inelastic vibration-rotational scattering is not needed which can reduce errors in backscatter and extinction retrieval methods.

A disadvantage, however, is that the RRL filters must have a much larger bandwidth than vibrational Raman filters in order to transmit the lidar return signals independently of temperature. As a consequence, the noise from sky background light reduces the advantage of the higher rotational backscattering cross section during daytime.

Up to now, measurements of the extinction coefficient and of the lidar ratio at $1064 \mathrm{~nm}$ are not very common. Most so called $3+2$ multiwavelength aerosol lidars measure the backscatter coefficient at three wavelengths (355, 532 , and $1064 \mathrm{~nm}$ ) and the extinction coefficient at two wavelengths (355 and $532 \mathrm{~nm}$ ) only. Haarig et al. [5] showed for the first time the use of RRL at $1064 \mathrm{~nm}$ in order to independently measure the extinction coefficient at $1064 \mathrm{~nm}$. However, this study was performed with a highpower lidar system [6] and presented in a first step a cirrus case.

In the following work, we employed the same filters that Haarig et al. [5] used in one of our Polly-XT systems in order to test if the RRL method would also be applicable for our smaller and automated systems.

\section{DESIGN OF INTERFERENCE FILTERS}

It can be calculated that the backscatter coefficient of the sum of both rotational-Raman wings of atmospheric gases at $1064 \mathrm{~nm}$ is of the order of $0.0023 \mathrm{Mm}^{-1} \mathrm{sr}^{-1}$ for normal pressure and a temperature of $300 \mathrm{~K}$. The interference filters that we use are centered on the Anti-Stokes lines to be able to angle-turn them to shorter wavelengths in case the manufacturing margins were too high. In this way, the required suppression of the elastically scattered light should still be achievable. Observing only the Anti-Stokes lines means that the rotational Raman backscatter coefficient which has to be measured is on the order of $0.001 \mathrm{Mm}^{-1} \mathrm{sr}^{-1}$. In contrast, the backscatter coefficient of the Cabannes line is $0.091 \mathrm{Mm}^{-1} \mathrm{sr}^{-1}$ for normal pressure and a temperature of $300 \mathrm{~K}$ [1]. Typical backscatter coefficients at $1064 \mathrm{~nm}$ are on the order of 1-5 $\mathrm{Mm}^{-1} \mathrm{sr}^{-1}$ for aerosols and of $500 \mathrm{Mm}^{-1} \mathrm{sr}^{-1}$ for 
water clouds. Hence, a suppression of the fundamental laser wavelength of $10^{-6}$ would only result in equal signals for the rotational Raman backscattering and for the elastic backscattering in the case of clouds. About four more orders of magnitude of suppression would be desirable to apply the Raman method [1, 2, 3, 4].

Figure 1 shows the transmission curve of our 1058-nm filters and the location of the rotationalRaman-scattering lines of Nitrogen and Oxygen from a fundamental laser wavelength of $1064.15 \mathrm{~nm}$. The filters were manufactured by Alluxa and have a peak transmission $>95 \%$. The full width at half maximum is $8 \mathrm{~nm}$, and was chosen so that the temperature dependence of the rotational Raman scattering is minimized. By theoretical design each filter should have an attenuation of the fundamental laser wavelength of $10^{-6}$. The measured attenuation of the finished filters however is only on the order of $10^{-4}$ as given by Alluxa.

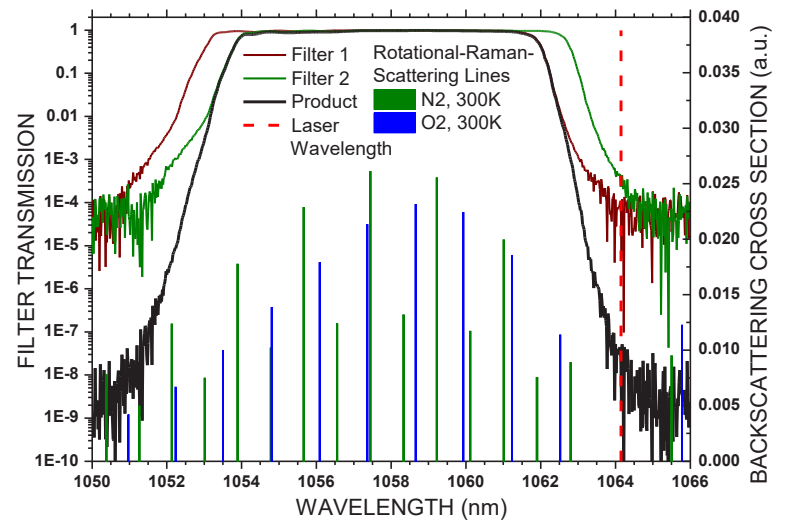

Figure 1: Transmission of both 1058-nm filters and their product. The locations of the laser wavelength and of the Anti-Stokes rotational Raman lines at $300 \mathrm{~K}$ are shown in addition.

As proposed by Veselovskii et al. [3] we used two filters to achieve a better suppression of the fundamental laser wavelength. In our case the theoretical suppression of $10^{-12}$ could not be achieved and is now only between $10^{-7}$ and $10^{-8}$. It can be seen, that both filters are indeed slightly shifted in their transmission window and Filter 2 should be a bit tilted for future measurements. For the following study however, we operated both filters at $90^{\circ}$ incident angles.

\section{THE LIDAR POLLY-XT}

The automated multiwavelength Raman polarization lidar Polly-XT has been developed at TROPOS [7, 8]. Nine of these lidar systems exist meanwhile. For this study we employed the lidars of the mobile ocean facility (OCEANET) of TROPOS and the Polly-XT of the National Observatory of Athens (NOA). Both systems are installed in standard 20-feet containers for more stable operations in maritime environments. In November 2016 Polly-XT-OCEANET was aboard the research vessel (RV) Polarstern crossing the Atlantic Ocean. In January 2017 both lidars were simultaneously operated at TROPOS, Leipzig.

In terms of the optical setup the lidar is completely build on a carbon fiber board which gives a light-weight but sturdy framework for the components. Figure 2 shows the schematically setup of the optical parts. The flash-lamp pumped and frequency doubled and tripled Nd:YAG laser emits radiation of about 200,100 , and $50 \mathrm{~mJ}$ at 1064, 532, and $355 \mathrm{~nm}$ wavelengths at $20 \mathrm{~Hz}$. The beam is expanded 8 times before it is transmitted into the atmosphere with a divergence of 0.2 mrad.

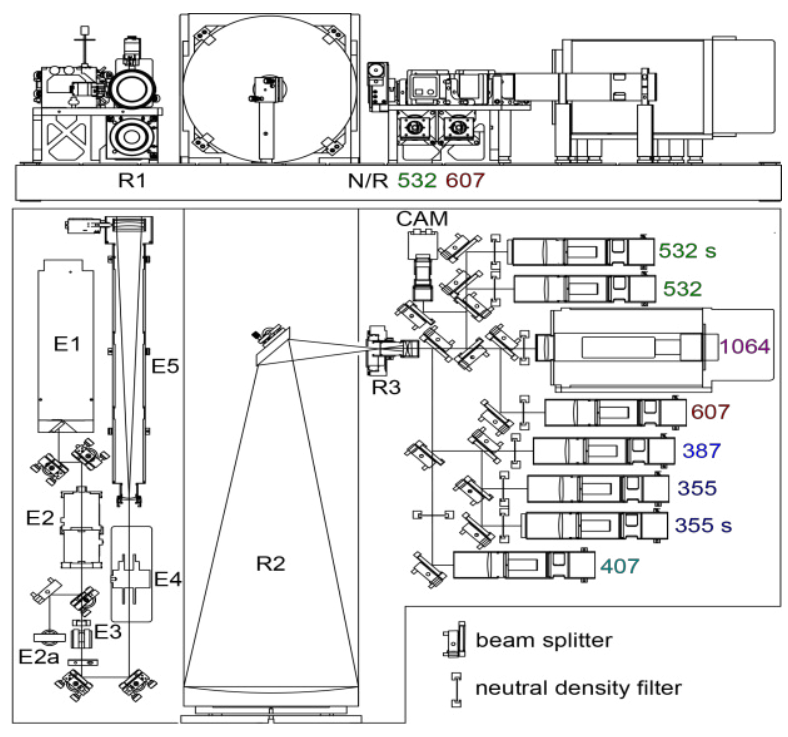

Figure 2: The optical setup of Polly-XT OCEANET and NOA. The upper part displays a top view and the lower part the front view of the system.

The receiving telescope (R2) has a diameter of $300 \mathrm{~mm}$, a field of view of $1 \mathrm{mrad}$, and a full overlap at around $800 \mathrm{~m}$ above the lidar. An automated depolarization calibration unit (R3) is 
placed in front of the field stop. By use of the $\Delta 90^{\circ}$ method absolute calibration is possible on a regular basis. Various dichroic beam splitters are used to separate all paths for the detection channels shown in Fig. 2. The detection is performed in photon-counting mode in all channels. For $1064 \mathrm{~nm}$ we operate a R3236 photomultiplier tube (PMT, Hamamatsu) cooled down to $-35^{\circ} \mathrm{C}$. This PMT has a quantum efficiency of only $0.03 \%$ at $1064 \mathrm{~nm}$ wavelength, but a very small dead-time of around $2.5 \mathrm{~ns}$. We employ a data acquisition that has been developed by Holger Linné of the Max-Planck Institute, Hamburg, Germany.

\section{FIRST RESULTS}

During our regular transects aboard RV Polarstern (cruise no. PS102) we occasionally exchanged the interference filter at $1064 \mathrm{~nm}$ of Polly-XT OCEANET by the two RRL filters. During the night from 25 to 26 November 2016 a marine boundary layer of $600 \mathrm{~m}$ height and on top a polluted dust layer up to $3.5 \mathrm{~km}$ height prevailed over the Atlantic Ocean about $500 \mathrm{~km}$ west of the coast of Guinea at $10^{\circ} \mathrm{N} 20^{\circ} \mathrm{W}$. Figure 3 presents the range-corrected signal and volume linear depolarization ratio at $532 \mathrm{~nm}$ from that night. The white lines indicate the almost 6-hour cloudfree time period (0015-0600 UTC) which we used to average the weak RRL signal.

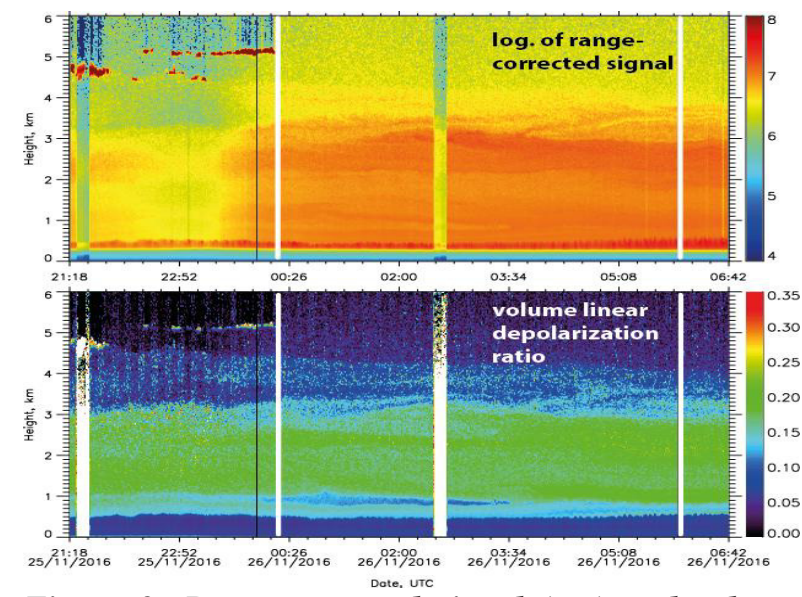

Figure 3: Range-corrected signal (top) and volume linear depolarization ratio (bottom) at $532 \mathrm{~nm}$ measured at $10^{\circ} \mathrm{N}, 20^{\circ} \mathrm{W}$ during the night from 25 to 26 Nov. 2016. At 0230 UTC an automated depolarization-calibration routine took place.

Figure 4 shows the optical products calculated from that period. The profiles of the lidar ratio $(S)$ and the particle linear depolarization ratio $\left(\delta_{\mathrm{P}}\right)$ show an occurrence of a marine layer $\left(S\right.$ and $\delta_{\mathrm{P}}$ rather low) at the surface and a dust layer with enhanced depolarization above. In the dust layer $S>60 \mathrm{sr}$ at $355 \mathrm{~nm}$ and $\delta_{\mathrm{P}}<21 \%$ which indicates that the dust is not "pure" but most likely mixed with smoke. Further analysis is not performed here.

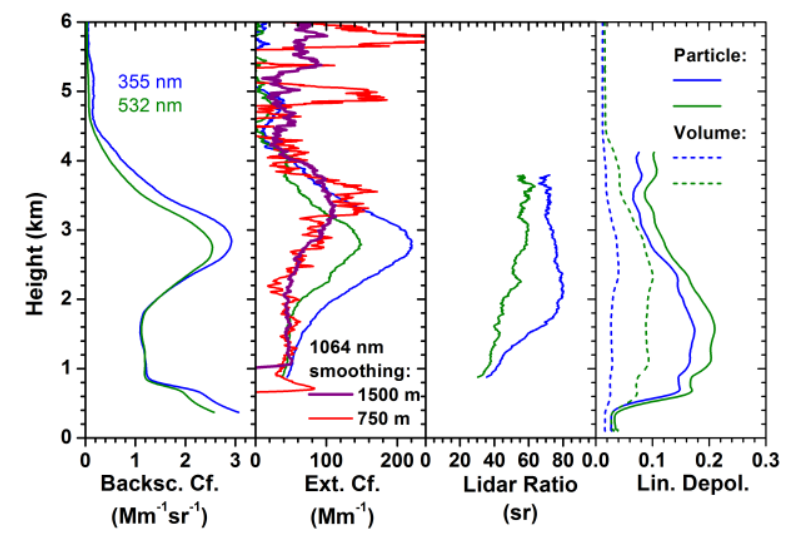

Figure 4: Optical products calculated from the 6-hour measurement shown in Fig. 3. The height resolution is $750 \mathrm{~m}$ for all profiles. The 1064- $\mathrm{nm}$ extinction is additionally shown at 1500 m height resolution.

The focus of this work lies on the 1064-nm particle extinction. Figure 4 shows the extinction calculated from the weak RRL signal with the Raman method for two different smoothing lengths (750 and $1500 \mathrm{~m}$, red and purple lines). Between 1 and $2 \mathrm{~km}$ height an extinction coefficient of $50 \mathrm{Mm}^{-1}$ is obtained which coincides with the values at 355 and $532 \mathrm{~nm}$ in the layer with the highest depolarization, i.e. in the dust-dominated layer the Angström exponent approaches 0 . The backscatter coefficient at $1064 \mathrm{~nm}$ could not be derived because this channel was replaced by the RRL channel.

It can be noted that the maximum of the 1064-nm extinction is found above the extinction maxima at 355 and $532 \mathrm{~nm}$. Moreover, this maximum is found where the backscatter gradient is strongest for 355 and $532 \mathrm{~nm}$ at around $3.5 \mathrm{~km}$ height. This fact suggests that the suppression of the elastically backscattered light is not sufficient and a significant crosstalk is still present. Consequently, the additional contribution of 1064-nm light affects the derivative of the logarithm of the RRL signal and thus affects the calculated extinction profile. 
In a second case, we present a measurement with two Polly-XT systems performed on 13 January 2017 in Leipzig. One of the lidars (OCEANET) was equipped with the RRL filters the other one (NOA) measured with its $1064 \mathrm{~nm}$ filter. With this combination we were able to measure the backscatter coefficient with the Raman method and thus the lidar ratio at $1064 \mathrm{~nm}$, too. Figure 5 shows the derived products at $1064 \mathrm{~nm}$ for the first time measured with Polly-XT.

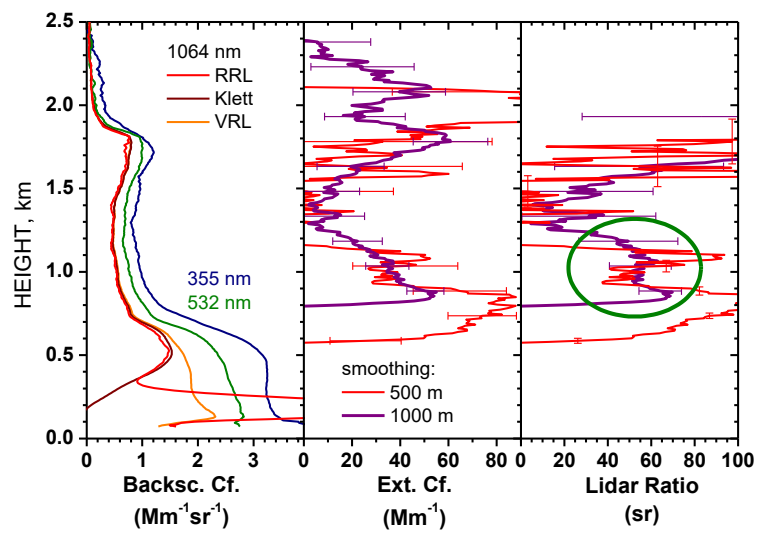

Figure 5: Lidar profiles measured with Polly-XT on 13 Jan. 2017 from 2035 to 2130 UTC in Leipzig. Left: backscatter coefficient at 355, 532, and $1064 \mathrm{~nm}$. Center: extinction coefficient at $1064 \mathrm{~nm}$ with two different smoothing lengths. Right: corresponding lidar ratios. The green circle indicates a "trustworthy" height region. Standard signal-noise errors are shown in addition.

The backscatter coefficients at 355,532 , and the orange $1064 \mathrm{~nm}$ profile were calculated with the vibrational-rotational Raman lidar (VRL) method. For $1064 \mathrm{~nm}$ we used the $607 \mathrm{~nm}$ signal. The Klett solution (brown) and the RRL solution (red) are also shown. The RRL profile at $1064 \mathrm{~nm}$ is erroneous below $600 \mathrm{~m}$ height because the two different lidars don't show the same overlap function. As seen in the previous case, the RRL filters show crosstalk with the elastically backscattering so that the extinction and lidar ratios are not yet trustworthy were gradients in the backscatter profiles are present. The green circle indicates a height region at which no gradient is present and a lidar ratio of 50-60 sr is obtained.

\section{OUTLOOK}

We found that the interference filter based RRL method at $1064 \mathrm{~nm}$ could be even applicable in a relatively small system like Polly-XT. However, the signals are very weak due to the low quantum efficiency of the 1064-nm PMT and an averaging time period of several hours is needed. Further improvements would include a more sensitive detector as well as additional blocking of the cross talk from elastically backscattered light at $1064 \mathrm{~nm}$.

\section{ACKNOWLEDGEMENT}

We gratefully thank Igor Veselovskii for his work on the calculation and the initial order of the RRL filters from Alluxa. The research leading to these results has received partly funding from the European Union Seventh Framework Programme (FP7/2007-2013) under grant agreement $\mathrm{n}^{\mathrm{o}} 262254$. The Polarstern cruise was supported by the Alfred-Wegener Institute (AWI_PS102_00). Polly-XT NOA received funding from the European Union's Seventh Framework Programme for research, technological development and demonstration (in the framework of BEYOND funded under: FP7-REGPOT-2012-2013-1) under grant agreement $\mathrm{n}^{\mathrm{o}} 316210$.

\section{References}

[1] Wandinger, U., 2005: Raman Lidar, in: Lidar - RangeResolved Optical Remote Sensing of the Atmosphere, edited by: C. Weitkamp, Springer - Series in Optical Sciences, New York, 241-271.

[2] Behrendt, A., T. Nakamura, M. Onishi, R. Baumgart, and T. Tsuda, 2002: Combined Raman lidar for the measurement of atmospheric temperature, water vapor, particle extinction coefficient, and particle backscatter coefficient. Appl. Opt., 41 (36), 7657-7666.

[3] Veselovskii, I., D. N. Whiteman, M. Korenskiy, A. Suvorina, D. Pérez-Ramírez, 2015: Use of rotational Raman measurements in multiwavelength aerosol lidar for evaluation of particle backscattering and extinction, Atmos. Meas. Tech., 8, 4111-4122.

[4] Ansmann, A. and D. Müller, 2005: Lidar and atmospheric aerosol particles, in: LIDAR - Range-resolved optical remote sensing of the atmosphere, edited by: C. Weitkamp, Springer Series in Optical Sciences, New York, 105-141.

[5] Haarig, M., R. Engelmann, A. Ansmann, I. Veselovskii, D. N. Whiteman, D. Althausen, 2016: $1064 \mathrm{~nm}$ rotational Raman lidar for particle extinction and lidar-ratio profiling: cirrus case study, Atmos. Meas. Tech., 9, 4269-4278.

[6] Althausen, D., D. Müller, A. Ansmann, U. Wandinger, H. Hube, E. Clauder, and S. Zörner, 2000: Scanning 6Wavelength 11-Channel Aerosol Lidar, J. Atmos. Oceanic Technol., 17, 1469-1482.

[7] Engelmann, R., T. Kanitz, H. Baars, B. Heese, D. Althausen, A. Skupin, U. Wandinger, M. Komppula, I. S. Stachlewska, V. Amiridis, E. Marinou, I. Mattis, H. Linné, A. Ansmann, 2016: The automated multiwavelength Raman polarization and water-vapor lidar PollyXT: the neXT generation, Atmos. Meas. Tech., 9, 1767-1784.

[8] http://polly.tropos.de (1 February 2017). 